Intervention fidelity in postintensive care follow-up consultations at ten sites in the RAPIT-trial

\title{
A mixed-methods evaluation
}

Jensen, Janet F; Overgaard, Dorthe; Bestle, Morten H; Christensen, Doris F; Rattray, Janice; Egerod, Ingrid

Published in:

Journal of Advanced Nursing

DOI:

10.1111/jan.13949

Publication date:

2019

Document version

Publisher's PDF, also known as Version of record

Document license:

CC BY

Citation for published version (APA):

Jensen, J. F., Overgaard, D., Bestle, M. H., Christensen, D. F., Rattray, J., \& Egerod, I. (2019). Intervention fidelity in postintensive care follow-up consultations at ten sites in the RAPIT-trial: A mixed-methods evaluation. Journal of Advanced Nursing, 75(4), 862-875. https://doi.org/10.1111/jan.13949 


\title{
Cardiovascular Risk Factors Associated With Venous Thromboembolism
}

\begin{abstract}
John Gregson, PhD; Stephen Kaptoge, PhD; Thomas Bolton, MSc; Lisa Pennells, PhD; Peter Willeit, MD; Stephen Burgess, PhD; Steven Bell, PhD; Michael Sweeting, PhD; Eric B. Rimm, ScD; Christopher Kabrhel, MD; Bengt Zöller, MD; Gerd Assmann, MD; Vilmundur Gudnason, MD; Aaron R. Folsom, MD; Volker Arndt, MD; Astrid Fletcher, MD; Paul E. Norman, MD; Børge G. Nordestgaard, MD; Akihiko Kitamura, PhD; Bakhtawar K. Mahmoodi, MD; Peter H. Whincup, MD; Matthew Knuiman, PhD; Veikko Salomaa, MD; Christa Meisinger, MD; Wolfgang Koenig, MD; Maryam Kavousi, MD; Henry Völzke, MD; Jackie A. Cooper, MBBS; Toshiharu Ninomiya, PhD; Edoardo Casiglia, MD; Beatriz Rodriguez, MD; Yoav Ben-Shlomo, MD; Jean-Pierre Després, MD; Leon Simons, MD; Elizabeth Barrett-Connor, MD; Cecilia Björkelund, MD; Marlene Notdurfter, MD; Daan Kromhout, PhD; Jackie Price, MD; Susan E. Sutherland, PhD; Johan Sundström, MD; Jussi Kauhanen, MD; John Gallacher, PhD; Joline W. J. Beulens, PhD; Rachel Dankner, MD; Cyrus Cooper, FMedSci; Simona Giampaoli, MD; Jason F. Deen, MD; Agustín Gómez de la Cámara, MD; Lewis H. Kuller, PhD; Annika Rosengren, PhD; Peter J. Svensson, MD; Dorothea Nagel, PhD; Carlos J. Crespo, MD; Hermann Brenner, MD; Juan R. Albertorio-Diaz, MA; Robert Atkins, MBBS; Eric J. Brunner, PhD; Martin Shipley, MSc; Inger Njølstad, MD; Deborah A. Lawlor, MSc; Yvonne T. van der Schouw, PhD; Randi Marie Selmer, PhD; Maurizio Trevisan, MD; W. M. Monique Verschuren, MD; Philip Greenland, MD; Sylvia Wassertheil-Smoller, PhD; Gordon D. O. Lowe, MD; Angela M. Wood, PhD; Adam S. Butterworth, PhD; Simon G. Thompson, PhD; John Danesh, FMedSci; Emanuele Di Angelantonio, FRCP; Tom Meade, FRS; for the Emerging Risk Factors Collaboration
\end{abstract}

IMPORTANCE It is uncertain to what extent established cardiovascular risk factors are associated with venous thromboembolism (VTE).

OBJECTIVE To estimate the associations of major cardiovascular risk factors with VTE, ie, deep vein thrombosis and pulmonary embolism.

DESIGN, SETTING, AND PARTICIPANTS This study included individual participant data mostly from essentially population-based cohort studies from the Emerging Risk Factors Collaboration (ERFC; 731728 participants; 75 cohorts; years of baseline surveys, February 1960 to June 2008; latest date of follow-up, December 2015) and the UK Biobank (421537 participants; years of baseline surveys, March 2006 to September 2010; latest date of follow-up, February 2016). Participants without cardiovascular disease at baseline were included. Data were analyzed from June 2017 to September 2018.

EXPOSURES A panel of several established cardiovascular risk factors.

MAIN OUTCOMES AND MEASURES Hazard ratios (HRs) per 1-SD higher usual risk factor levels (or presence/absence). Incident fatal outcomes in ERFC (VTE, 1041; coronary heart disease [CHD], 25131) and incident fatal/nonfatal outcomes in UK Biobank (VTE, 2321; CHD, 3385). Hazard ratios were adjusted for age, sex, smoking status, diabetes, and body mass index (BMI).

RESULTS Of the 731728 participants from the ERFC, 403396 (55.1\%) were female, and the mean (SD) age at the time of the survey was 51.9 (9.0) years; of the 421537 participants from the UK Biobank, 233699 (55.4\%) were female, and the mean (SD) age at the time of the survey was 56.4 (8.1) years. Risk factors for VTE included older age (ERFC: HR per decade, 2.67; 95\% Cl, 2.45-2.91; UK Biobank: HR, 1.81; 95\% Cl, 1.71-1.92), current smoking (ERFC: HR, 1.38; $95 \% \mathrm{Cl}, 1.20-1.58$; UK Biobank: HR, 1.23; $95 \% \mathrm{Cl}, 1.08-1.40$ ), and BMI (ERFC: HR per 1-SD higher BMI, 1.43; 95\% Cl, 1.35-1.50; UK Biobank: HR, 1.37; 95\% Cl, 1.32-1.41). For these factors, there were similar HRs for pulmonary embolism and deep vein thrombosis in UK Biobank (except adiposity was more strongly associated with pulmonary embolism) and similar HRs for unprovoked vs provoked VTE. Apart from adiposity, these risk factors were less strongly associated with VTE than CHD. There were inconsistent associations of VTEs with diabetes and blood pressure across ERFC and UK Biobank, and there was limited ability to study lipid and inflammation markers.

CONCLUSIONS AND RELEVANCE Older age, smoking, and adiposity were consistently associated with higher VTE risk.

JAMA Cardiol. 2019;4(2):163-173. doi:10.1001/jamacardio.2018.4537

Published online January 16, 2019.

Supplemental content

Author Affiliations: Author affiliations are listed at the end of this article.

Group Information: Investigators of the Emerging Risk Factors Collaboration are listed at the end of this article.

Corresponding Author: Emanuele Di Angelantonio, FRCP, MRC/BHF Cardiovascular Epidemiology Unit, Department of Public Health and Primary Care, University of Cambridge, Cambridge CB1 8RN, United Kingdom (erfc@phpc.cam.ac. $u k)$. 
$\mathrm{V}$ enous thromboembolism (VTE), consisting of deep vein thrombosis (DVT) or pulmonary embolism (PE), is a major clinical burden. Globally, there are about 10 million cases every year, and it is the third leading vascular disease after myocardial infarction and stroke. ${ }^{1}$ Pulmonary embolism is a manifestation of VTE and is responsible for most VTE deaths. ${ }^{2}$ In recent years, efforts to prevent VTE have broadened from focusing mainly on hospital-based risk factors (eg, recent prior surgery, cancer, and congestive heart failure) toward adoption of heart-healthy lifestyles. ${ }^{3}$ This perspective has challenged traditional views of venous and arterial thrombosis as distinct pathologies, encouraging prevention strategies that concomitantly address VTE and arterial thrombosis. ${ }^{2,4}$ However, there is uncertainty about the extent to which venous and arterial thrombosis share cardiovascular risk factors, as studies have reported conflicting findings. ${ }^{5-15}$ Interpretation has been complicated by the use of retrospective case-control designs, limited statistical power, and/or inability to compare VTE and arterial disease outcomes within the same cohorts. ${ }^{16-26}$

Analyzing data from more than 1.1 million participants in 76 prospective studies, we investigated associations of several established cardiovascular risk factors with the incidence of VTE outcomes. We aimed to address 2 principal questions: What are the associations of major cardiovascular risk factors with VTE outcomes (including subtypes)? How do these associations compare with those for coronary heart disease (CHD), a manifestation of arterial thrombotic disease?

\section{Methods}

\section{Data Sources and Participant Inclusion}

We analyzed data from the Emerging Risk Factors Collaboration (ERFC), a consortium of prospective cohort studies with information on a variety of risk factors, and the UK Biobank, a single large prospective study. Both the ERFC and UK Biobank have been described previously. ${ }^{27,28}$ Both data sources involve a prospective cohort study design and accessible individual participant data, enabling standardized and detailed analyses using a common protocol, including definitions for VTE and CHD outcomes. However, we conducted parallel (rather than pooled) analyses of the 2 sources because of potentially important differences in their approaches to VTE ascertainment, ie, the ERFC recorded only fatal VTE outcomes while UK Biobank recorded both fatal and nonfatal VTE outcomes, most of which were nonfatal. Information about each of the 76 studies contributing to this analysis is provided in the eAppendix in the Supplement. The study was designed and conducted by the Emerging Risk Factors Collaboration academic coordinating center, and it was approved by the Cambridgeshire Ethics Review Committee. Informed consent was obtained from participants in each of the cohorts contributing to the analysis.

Participants in the contributing studies were eligible for inclusion in the current analysis if they met all of the following criteria: (1) had recorded information on several established cardiovascular risk factors (as a minimum, information on age, sex, smoking status, history of diabetes, and body mass index [BMI]),

\section{Key Points}

Question To what extent are established cardiovascular risk factors associated with risk of venous thromboembolism (VTE)?

Findings In this analysis of individual participant data from the Emerging Risk Factors Collaboration and the UK Biobank including 1.1 million participants, among a panel of several established cardiovascular risk factors, older age, smoking, and greater adiposity were consistently associated with higher VTE risk.

Meaning There is overlap in at least some of the major population determinants of important venous and arterial thrombotic diseases.

(2) did not have a known baseline history of cardiovascular disease (CVD; defined as CHD, other heart disease, stroke, transient ischemic attack, peripheral vascular disease, or cardiovascular surgery) or VTE (defined as DVT or PE), and (3) had at least 1 year of follow-up data after baseline.

In the ERFC, only fatal VTE events were recorded. Ascertainment was based on death certificates supplemented in 56 studies by medical records, findings on autopsy, and other sources. In UK Biobank, fatal and nonfatal VTEs were ascertained through linkage with routinely collected medical records. We attempted to subcategorize VTEs as provoked and unprovoked using a pragmatic approach that required inference from routine records (eAppendix in the Supplement). Briefly, following the example of previous work, ${ }^{13}$ we defined VTE as provoked if, in the 90-day period preceding the VTE, the participant was recorded as having a malignant neoplasm (per cancer registry data); starting or ending a hospital episode with a main diagnosis code relating to malignant neoplasm, heart failure, infectious disease, or trauma; or having a hospital episode that included certain types of surgical procedures. The specific International Statistical Classification of Diseases and Related Health Problems (ICD) codes and Classification of Interventions and Procedures codes that are included in our definition are summarized in the eAppendix in the Supplement. All studies used definitions of CHD based on World Health Organization (or similar) criteria. In registering fatal outcomes, the contributing studies classified deaths according to the primary cause (or, in its absence, the underlying cause) on the basis of $I C D-8, I C D-9$, and $I C D-10$ codes to at least 3 digits or according to study-specific classification systems. In the ERFC, baseline surveys were given between February 1960 and June 2008, and the date of latest follow-up was December 2015 (median, 2014 across studies); in the UK Biobank, baseline surveys were given between March 2006 and September 2010, and the date of latest follow-up was February 2016.

\section{Statistical Analysis}

For continuous risk factors, we calculated hazard ratios (HRs) per 1-SD higher usual risk factor level. For binary risk factors, we compared presence vs absence of the factor. Cox proportional hazards regression models were adjusted for age, smoking status, history of diabetes, and BMI and stratified by study, sex, and (when appropriate) trial arm. To avoid overadjustment, we did not routinely adjust for systolic blood pressure or lipid measurements (which, for example, can mediate the effects of adiposity). Similarly, we did not adjust for BMI when analyzing other 
measures of adiposity (eg, waist circumference). Participants in the UK Biobank were censored at first nonfatal CVD event, death, or study exit, whichever occurred first. Participants in ERFC were censored at death or study exit. Because nonfatal CVD may result in hospitalization (which may, in turn, lead to VTE outcomes), sensitivity analyses additionally censored at the first nonfatal CVD event in ERFC.

To correct for regression dilution caused by variability in levels of continuous risk factors, we regressed serial measurements of risk factors obtained from up to 146749 participants in ERFC (mean interval, 8.4 years) and up to 24235 participants in UK Biobank (mean interval, 5.2 years) on baseline levels of the relevant characteristics. Correction for within-person variation in risk factors was achieved by use of conditional expectations of long-term average levels (termed usual levels) of the risk factors, which were predicted from regression calibration models and used in estimation of HRs, as described previously. ${ }^{29}$

To characterize shapes of associations, HRs calculated within overall fifths of baseline exposure values were plotted against mean usual values of the relevant risk factor within each fifth. We used the Plummer method to estimate 95\% CIs from the variances that corresponded to the amount of information underlying each group (including the reference category). ${ }^{30}$

Because a further aim of the study was to compare associations of risk factors with VTE vs CHD outcomes within the same cohorts, we defined a competing risk model using a record duplication approach, allowing for simultaneous causespecific hazard regression to estimate cause-specific HRs for each type of event. In ERFC, we stratified the cause-specific regression model by cohort to allow for a different baseline hazard function in each study. We tested for differences in associations with VTE vs CHD based on the interaction between each exposure variable and the event type indicator variable. ${ }^{31}$

Analyses were carried out in Stata version 13 (StataCorp). Because of the number of statistical tests done, principal emphasis was given to findings with a $P$ value less than .001 , and all $P$ values were 2 -sided.

\section{Results}

Data were available for 731728 participants from 75 ERFC cohorts and 421537 participants from UK Biobank (Table) (eTable 1 in the Supplement). The mean (SD) age at baseline was 51.9 (9.0) years in ERFC and 56.4 (8.1) years in UK Biobank; 403396 participants (55.1\%) in the ERFC and 233699 (55.4\%) in UK Biobank were female. Most participants in ERFC were enrolled in either Europe (369 757 of 731728 [50.5\%]) or North America (315 278 of 731728 [43.1\%]). During a median follow-up of 15.4 years, 1041 fatal VTE events and 25131 fatal CHD events were recorded in the ERFC. In UK Biobank, 2321 fatal or nonfatal VTE events and 3385 fatal or nonfatal CHD events were recorded during a median follow-up of 6.1 years.

Associations of several risk factors with VTE were approximately log-linear (Figure 1). Older age was associated with higher risk of VTE, with an approximately 2.8-fold higher risk per decade in ERFC and 1.8-fold higher risk per decade in UK Biobank (Figure2). Compared with females, males had a higher risk of VTE in UK Biobank (HR, 1.44; 95\% CI, 1.32-1.56), somewhat less so in ERFC (HR, 1.17; 95\% CI, 0.998-1.38). Current smoking was associated with VTE risk in ERFC (HR, 1.38; 95\% CI, 1.20-1.58), but somewhat less so in UK Biobank (HR, 1.23; 95\% CI, 1.08-1.40). Markers of adiposity (BMI, waist-to-hip ratio, and waist circumference) were positively associated with higher VTE risk in both ERFC and UK Biobank. For example, HRs per 1-SD higher BMI were 1.43 (95\% CI, 1.35-1.50) in ERFC and 1.37 (95\% CI, 1.32-1.41) in UK Biobank. Current alcohol consumption was inversely associated with VTE risk in both ERFC (HR, 0.75; 95\% CI, 0.61-0.93) and UK Biobank (HR, 0.82; 95\% CI, 0.71-0.94). In exploratory analyses restricted to current drinkers in UK Biobank (which should limit the effects of certain residual biases, such as reverse causality related to sick quitters ${ }^{32}$ ), we found that the inverse association between amount of alcohol consumed and VTE risk persisted (eFigure 1 in the Supplement).

By contrast, for some other risk factors we studied, we noted potentially directionally discordant associations across ERFC and UK Biobank. For example, 1-SD higher systolic blood pressure was not associated with risk of VTE in ERFC (HR, 1.07; 95\% CI, 0.951.19) but was inversely associated with risk of VTE in UK Biobank (HR, 0.83; 95\% CI, 0.77-0.90). Conversely, 1-SD higher diastolic blood pressure was associated with higher risk of VTE in ERFC (HR, 1.26; 95\% CI, 1.11-1.42) but was not associated with risk of VTE in UK Biobank (HR, 0.94; 95\% CI, 0.87-1.02). In ERFC, history of diabetes was associated with higher risk of VTE (HR, 1.69; 95\% CI, 1.33-2.16) as was 1-SD higher fasting baseline glucose concentration (HR, 1.27; 95\% CI, 1.08-1.48), while in UK Biobank, history of diabetes was inversely associated with risk of VTE (HR, 0.83; 95\% CI, 0.69-0.99). To investigate whether these discordant associations chiefly reflected the different VTE outcomes recorded across ERFC and UK Biobank, we restricted analysis to the UK Biobank (which had recorded both fatal and nonfatal VTE outcomes). In UK Biobank-specific analyses, we found a similar pattern of difference of HRs for fatal vs nonfatal VTEs with blood pressure and diabetes to that observed in our comparison across ERFC and UK Biobank (eFigure 2 in the Supplement). This result suggests that blood pressure and diabetes may have differing associations with fatal vs nonfatal VTEs.

At the time of our analysis, data on plasma biomarkers were available in the ERFC but not in UK Biobank (Figure 2). In the ERFC, apolipoprotein B, apolipoprotein A, and lipoprotein(a) levels each showed suggestively inverse associations with risk of VTE, whereas triglyceride, non-high-density lipoprotein cholesterol, and high-density lipoprotein cholesterol levels each showed no associations. Fasting glucose, C-reactive protein, and fibrinogen levels were each associated with higher risk of VTE.

In analyses comparing PE with DVT, higher BMI and higher waist circumference had stronger associations with PE than DVT (Figure 3). Further analyses that subcategorized VTE outcomes as provoked vs unprovoked in UK Biobank did not reveal major differences in the associations of most CVD risk factors, with the exceptions of older age and male sex (Figure 4).

In analyses comparing VTE with CHD outcomes, associations were stronger for CHD in both ERFC and UK Biobank for most risk factors, including age, male sex, current smoking status, history of diabetes, higher systolic and diastolic blood 


\begin{tabular}{|c|c|c|c|c|c|}
\hline \multirow[b]{2}{*}{ Characteristic } & \multicolumn{3}{|l|}{ ERFC } & \multicolumn{2}{|c|}{ UK Biobank ${ }^{\mathrm{a}}$} \\
\hline & $\begin{array}{l}\text { No. of } \\
\text { Cohorts }\end{array}$ & No. & Measure & No. & Measure \\
\hline \multicolumn{6}{|c|}{ Demographic and lifestyle factors, №. (\%) } \\
\hline Age at baseline survey, mean (SD), y & 75 & 731728 & $51.9(9.0)$ & 421537 & $56.4(8.1)$ \\
\hline Male & 70 & 731728 & $328332(44.9)$ & 421537 & $187838(44.6)$ \\
\hline Current smoker & 75 & 731728 & $222016(30.3)$ & 421537 & $43847(10.4)$ \\
\hline History of diabetes & 74 & 731728 & $25982(3.6)$ & 421537 & $17622(4.2)$ \\
\hline Current alcohol drinker & 58 & 386831 & $271499(70.2)$ & 421197 & 389507 (92.5) \\
\hline \multicolumn{6}{|l|}{$\begin{array}{l}\text { Anthropometric and physical markers, } \\
\text { mean (SD) }\end{array}$} \\
\hline Systolic blood pressure, $\mathrm{mm} \mathrm{Hg}$ & 73 & 566724 & $131(19)$ & 421179 & 137 (19) \\
\hline Diastolic blood pressure, $\mathrm{mm} \mathrm{Hg}$ & 72 & 565895 & $80.0(10.9)$ & 421181 & $82.2(10.1)$ \\
\hline Body mass index ${ }^{b}$ & 75 & 731728 & $25.4(4.2)$ & 421537 & $27.2(4.7)$ \\
\hline Waist-to-hip ratio & 34 & 264787 & $0.85(0.08)$ & 421440 & $0.87(0.09)$ \\
\hline Waist circumference, $\mathrm{cm}$ & 36 & 265465 & $87.6(12.5)$ & 421464 & $89.6(13.2)$ \\
\hline \multicolumn{6}{|l|}{ Lipid-related markers, mean (SD) } \\
\hline Total cholesterol levels, mg/dL & 68 & 455177 & $222.0(43.6)$ & NA & NA \\
\hline Non-HDL cholesterol levels, $\mathrm{mg} / \mathrm{dL}$ & 57 & 311888 & $171.0(44.8)$ & NA & NA \\
\hline HDL cholesterol levels, mg/dL & 57 & 312207 & $52.9(14.7)$ & NA & NA \\
\hline Log triglyceride levels, $\mathrm{mg} / \mathrm{dL}^{\mathrm{c}}$ & 56 & 322096 & $4.79(0.53)$ & NA & NA \\
\hline Apolipoprotein B levels, mg/dL & 20 & 80712 & $103(29)$ & NA & NA \\
\hline Apolipoprotein A1 levels, mg/dL & 20 & 84483 & $137(33)$ & NA & NA \\
\hline Log Lp(a) levels, mg/dL ${ }^{d}$ & 18 & 66382 & $2.20(1.20)$ & NA & NA \\
\hline \multicolumn{6}{|l|}{$\begin{array}{l}\text { Metabolic and inflammatory markers, } \\
\text { mean (SD) }\end{array}$} \\
\hline Fasting glucose levels, mg/dL & 33 & 130322 & $88.5(24.3)$ & NA & NA \\
\hline Log CRP levels, mg/L ${ }^{\mathrm{e}}$ & 28 & 70855 & $0.46(1.07)$ & NA & NA \\
\hline Fibrinogen levels, mg/dL & 29 & 115002 & $241.2(68.7)$ & NA & NA \\
\hline Albumin levels, g/dL & 25 & 115309 & $4.29(0.39)$ & NA & NA \\
\hline \multicolumn{6}{|l|}{$\begin{array}{l}\text { Study period, median (5th centile-95th } \\
\text { (entile) }\end{array}$} \\
\hline Baseline survey year & 75 & 731728 & $\begin{array}{l}1986 \\
(1971-2000)\end{array}$ & 421537 & $\begin{array}{l}2009 \\
(2007-2010)\end{array}$ \\
\hline Latest follow-up year & 75 & 731728 & $\begin{array}{l}2004 \\
(1989-2011)\end{array}$ & 421537 & $\begin{array}{l}2016 \\
(2016-2016)\end{array}$ \\
\hline \multicolumn{6}{|l|}{ Outcomes, No. } \\
\hline $\begin{array}{l}\text { Time to event or censoring, median (5th } \\
\text { centile-95th centile), } y\end{array}$ & 75 & 731728 & $15.4(5.5-32.0)$ & 421537 & $6.1(4.8-7.5)$ \\
\hline Total follow up, person-years in millions & 75 & 731728 & 12.807 & 421537 & 2.566 \\
\hline Non-fatal MI & $N A^{g}$ & NA & NA & 421537 & 2808 \\
\hline Fatal CHD & 75 & 731728 & 25131 & 421537 & 577 \\
\hline VTE & 75 & 731728 & 1041 & 421537 & 2321 \\
\hline Nonfatal VTE & $N A^{g}$ & NA & NA & 421537 & 2234 \\
\hline Fatal VTE & 75 & 731728 & 1041 & 421537 & 87 \\
\hline Pulmonary embolism & 75 & 731728 & 855 & 421537 & 1273 \\
\hline Deep venous thromboembolism & 75 & 731728 & 186 & 421537 & 1048 \\
\hline Unprovoked VTE & NA & NA & NA & 421537 & 1465 \\
\hline Provoked VTE & NA & NA & NA & 421537 & 856 \\
\hline
\end{tabular}

Abbreviations: CHD, coronary heart disease; CRP, C-reactive protein; ERFC, Emerging Risk Factors Collaboration; HDL, high-density lipoprotein; Lp(a), lipoprotein(a); $\mathrm{MI}$, myocardial infarction; NA, not applicable; $\mathrm{PE}$, pulmonary embolism; VTE, venous thromboembolism. SI conversion factor: To convert cholesterol to millimoles per liter, multiply by 0.0259 ; triglycerides to millimoles per liter, multiply by 0.0113 ; apolipoprotein to grams per liter, multiply by $0.01 ; \mathrm{Lp}(\mathrm{a})$ to micromoles per liter, multiply by 0.0357 ; fasting glucose to micromoles per liter, multiply by 0.0555; CRP to nanomoles per liter, multiply by 9.524 ; fibrinogen to grams per liter, multiply by 0.01 ; and albumin to grams per liter, multiply by 10 .

${ }^{a}$ At the time of these analyses, data on plasma biomarkers were not available in UK Biobank.

${ }^{\mathrm{b}}$ Body mass index calculated as weight in kilograms divided by height in meters squared.

${ }^{\mathrm{C}}$ Median (interquartile range) triglyceride level was 117 (82-170) $\mathrm{mg} / \mathrm{dL}$.

${ }^{\mathrm{d}}$ Median (interquartile range) $\mathrm{Lp}(\mathrm{a})$ level was $9(4-25) \mathrm{mg} / \mathrm{dL}$.

e Median (interquartile range) CRP level was $1.48(0.72-3.15) \mathrm{mg} / \mathrm{dL}$.

${ }^{f}$ Follow-up and outcome summaries among participants with complete data on age, sex, smoking status, history of diabetes, and body mass index.

${ }^{\mathrm{g}}$ Most of the studies in ERFC did not ascertain nonfatal VTE outcomes: hence, analyses in ERFC were restricted to comparison of fatal CHD outcomes only. pressure, and proatherogenic lipid levels (eFigures 3 and 4 in the Supplement). In contrast, higher BMI and waist circumference had somewhat stronger associations with VTE compared with $\mathrm{CHD}$, whereas circulating inflammatory markers were associated with both conditions to a broadly similar extent (eFigures 3 and 4 in the Supplement). Findings were broadly similar in sensitivity analyses that did not adjust for BMI (eTable 2 in the Supplement), excluded participants with history of cancer diagnosis at baseline (eFigure 5 in the Supplement), censored for first CVD events in ERFC (eFigure 6 in the
Supplement), and used baseline levels of risk factors, except for the expected decrease in the magnitudes of association when not correcting for within-person variability in the continuous variables (eFigures 7-9 in the Supplement).

\section{Discussion}

In this analysis of individual-level data on several established cardiovascular risk factors from more than 1.1 million 

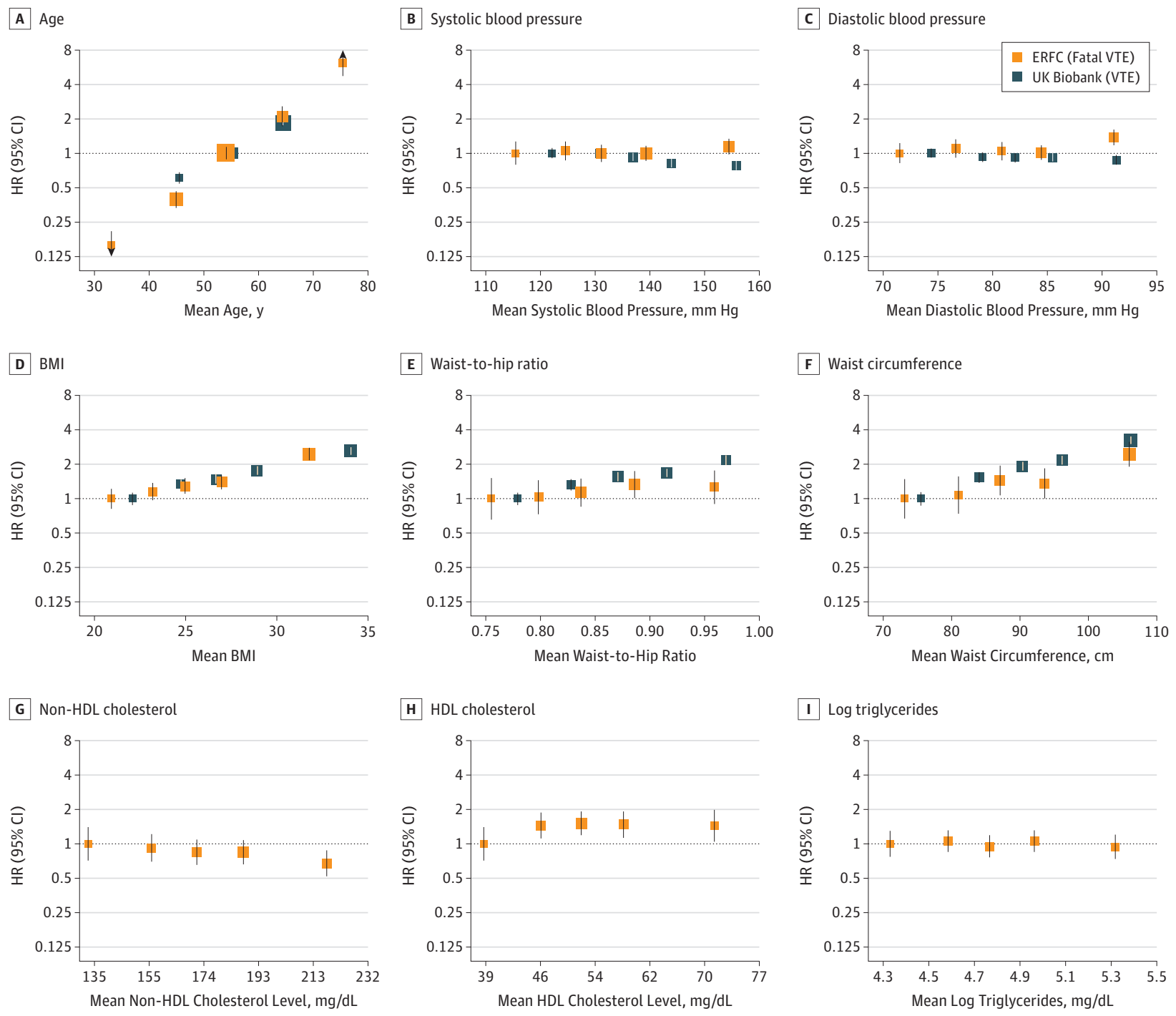

All comparisons were adjusted for age, sex, smoking status, history of diabetes, and usual body mass index (BMl; calculated as weight in kilograms divided by height in meters squared) (waist-to-hip ratio and waist circumference were not adjusted for usual BMI). The reference category is age 50 to 59 years for age and is the bottom fifth for all other continuous variables. Associations involve

Emerging Risk Factors Collaboration (ERFC) data for fatal VTE and UK Biobank data for VTE. Data on cholesterol and triglyceride levels were unavailable in UK Biobank at the time of analysis. Most UK Biobank participants were aged between 40 and 69 years at baseline. The dotted line indicates the reference value. HDL indicates high-density lipoprotein. participants in 76 cohorts, we found that older age, smoking, and higher levels of adiposity were clearly associated with higher risk of VTE. These findings suggest that there is overlap in at least some major population determinants of important venous and arterial thrombotic diseases.

Our study characterized dose-response associations between several clinical measures of adiposity (eg, waist circumference and BMI) and VTE risk and showed no evidence of a threshold below which leaner body habitus stopped being associated with lower VTE risk. The association of obesity with VTE is supported by previous mendelian randomization studies of genetic variants associated with increased adiposity, which are also associated with increased risk of VTE. ${ }^{33,34}$ Furthermore, we found that associations of BMI and waist circumference were somewhat stronger with PE vs DVT and about twice as strong with VTE vs CHD. These data suggest that efforts to combat the entire spectrum of obesity and overweight should yield important benefits for VTE prevention.

As regards risk behaviors, our study confirmed the known association of current smoking with risk of VTE. ${ }^{9,13}$ This association was similar in magnitude for PE and DVT outcomes but weaker than that observed for CHD. Previous studies have suggested that much of the excess risk of VTE in smokers was because of increased hospitalization for smoking-related diseases, including cancer. ${ }^{35,36}$ However, in our analysis, smoking was similarly associated with both provoked and unprovoked VTE; furthermore, HRs did not change appreciably 


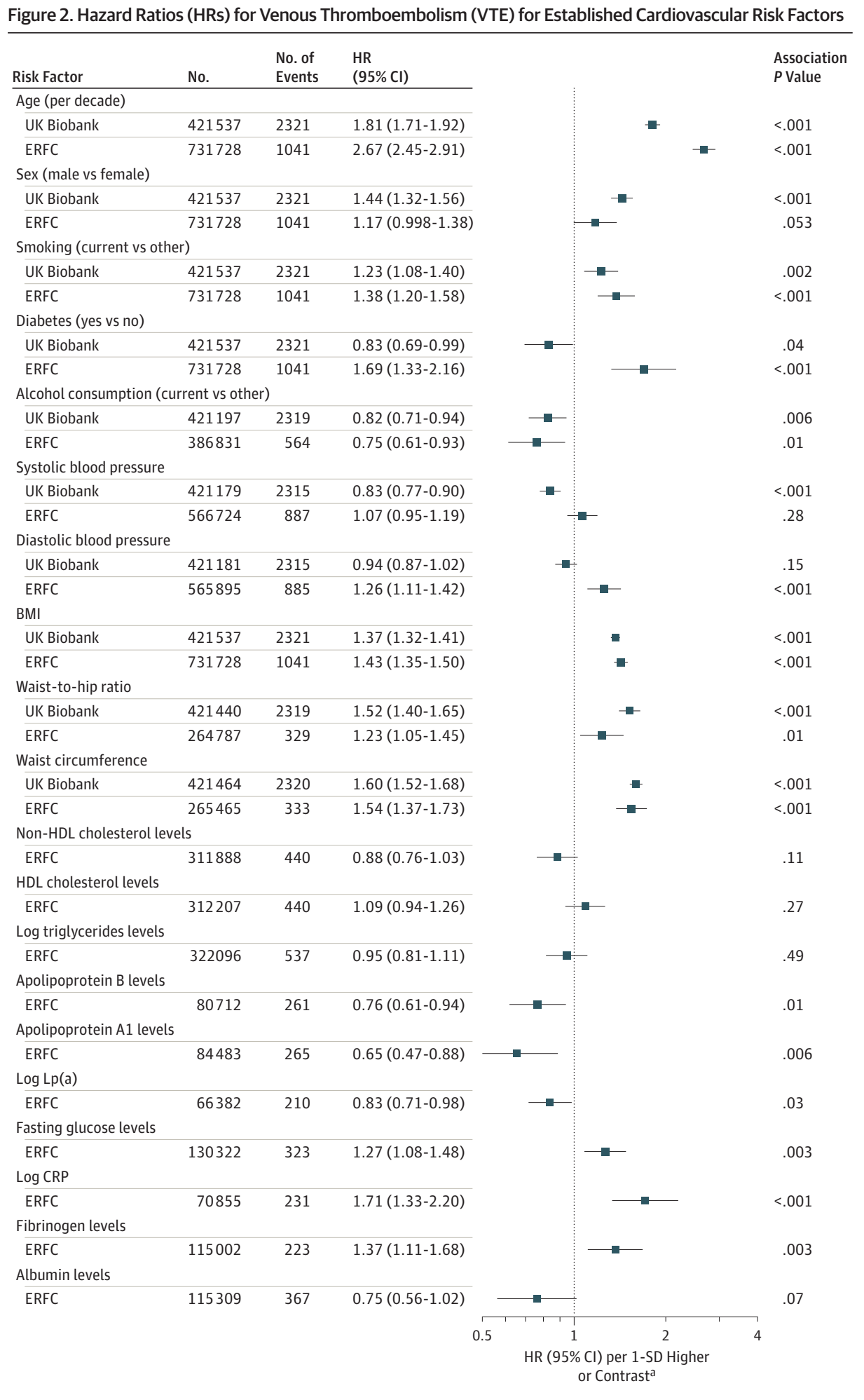

All comparisons were adjusted for age, sex, smoking status, history of diabetes, and usual body mass index (BMI) (waist-to-hip ratio and waist circumference were not adjusted for usual BMI). Associations involve Emerging Risk Factors Collaboration (ERFC) data for fatal VTE and UK Biobank data for VTE. CRP indicates C-reactive protein; $\mathrm{HDL}$, high-density lipoprotein; Lp(a), lipoprotein(a).

${ }^{\text {a }}$ Hazard ratios are presented per 1-SD higher usual risk factor level unless otherwise indicated. after exclusion of participants with history of cancer diagnosis at baseline. We also noted a pattern of association between alcohol consumption and VTE similar to that reported in previous studies of alcohol consumption and nonfatal myocardial infarction. ${ }^{32,37,38}$ (By contrast, alcohol consumption has previously been positively associated with risks of fatal coro- nary disease, stroke, and heart failure.) Although previous studies have reported that moderate alcohol consumption is associated with lower levels of hemostatic factors (eg, fibrinogen, factor VII, and von Willebrand factor), ${ }^{39,40}$ further studies are needed to determine whether moderate alcohol consumption has a causal role in VTE. 


\begin{tabular}{|c|c|c|c|c|c|c|}
\hline Risk Factor & No. & $\begin{array}{l}\text { No. of } \\
\text { Events }\end{array}$ & $\begin{array}{l}\mathrm{HR} \\
(95 \% \mathrm{Cl})\end{array}$ & & & $\begin{array}{l}\text { Difference } \\
P \text { Value }\end{array}$ \\
\hline \multicolumn{7}{|c|}{ Age (per decade) } \\
\hline $\mathrm{PE}$ & 421537 & 1273 & $1.91(1.76-2.06)$ & & 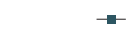 & \multirow[t]{2}{*}{.051} \\
\hline DVT & 421537 & 1048 & $1.70(1.57-1.85)$ & & $\rightarrow$ & \\
\hline \multicolumn{7}{|c|}{ Sex (male vs female) } \\
\hline $\mathrm{PE}$ & 421537 & 1273 & $1.37(1.23-1.54)$ & & -- & \multirow[t]{2}{*}{.24} \\
\hline DVT & 421537 & 1048 & $1.52(1.34-1.72)$ & & $\rightarrow$ & \\
\hline \multicolumn{7}{|c|}{ Smoking (current vs other) } \\
\hline $\mathrm{PE}$ & 421537 & 1273 & $1.29(1.09-1.53)$ & & \multirow{2}{*}{$=-$} & \multirow[t]{2}{*}{.40} \\
\hline DVT & 421537 & 1048 & $1.16(0.95-1.40)$ & & & \\
\hline \multicolumn{7}{|c|}{ Diabetes (yes vs no) } \\
\hline $\mathrm{PE}$ & 421537 & 1273 & $0.74(0.57-0.95)$ & $\longrightarrow$ & & \multirow[t]{2}{*}{.20} \\
\hline DVT & 421537 & 1048 & $0.94(0.72-1.23)$ & $\rightarrow$ & 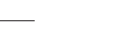 & \\
\hline \multicolumn{7}{|c|}{ Alcohol consumption (current vs other) } \\
\hline $\mathrm{PE}$ & 421197 & 1272 & $0.90(0.74-1.10)$ & $\rightarrow$ & & \multirow[t]{2}{*}{.15} \\
\hline DVT & 421197 & 1047 & $0.73(0.60-0.90)$ & $=$ & & \\
\hline \multicolumn{7}{|c|}{ Systolic blood pressure } \\
\hline $\mathrm{PE}$ & 421179 & 1268 & $0.78(0.70-0.86)$ & $\rightarrow$ & & \multirow[t]{2}{*}{.046} \\
\hline DVT & 421179 & 1047 & $0.91(0.81-1.02)$ & $\rightarrow$ & & \\
\hline \multicolumn{7}{|c|}{ Diastolic blood pressure } \\
\hline $\mathrm{PE}$ & 421181 & 1268 & $0.96(0.86-1.07)$ & $\rightarrow$ & & \multirow[t]{2}{*}{.60} \\
\hline DVT & 421181 & 1047 & $0.92(0.81-1.04)$ & $\rightarrow$ & & \\
\hline \multicolumn{7}{|l|}{ BMI } \\
\hline $\mathrm{PE}$ & 421537 & 1273 & $1.44(1.38-1.50)$ & & - & \multirow[t]{2}{*}{.001} \\
\hline DVT & 421537 & 1048 & $1.28(1.21-1.35)$ & & $=$ & \\
\hline \multicolumn{7}{|c|}{ Waist-to-hip ratio } \\
\hline $\mathrm{PE}$ & 421440 & 1272 & $1.67(1.50-1.85)$ & & $\rightarrow$ & \multirow[t]{2}{*}{.01} \\
\hline DVT & 421440 & 1047 & $1.35(1.20-1.53)$ & & $\rightarrow$ & \\
\hline \multicolumn{7}{|c|}{ Waist circumference } \\
\hline $\mathrm{PE}$ & 421464 & 1273 & $1.74(1.63-1.86)$ & & 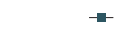 & \multirow[t]{2}{*}{$<.001$} \\
\hline \multirow[t]{3}{*}{ DVT } & 421464 & 1047 & $1.43(1.33-1.54)$ & & 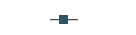 & \\
\hline & & & & .5 & 2 & \multirow[t]{2}{*}{4} \\
\hline & & & & $\mathrm{HR}(9$ & $\begin{array}{l}6 \mathrm{Cl} \text { ) per 1-SD } \\
\text { or Contrast }\end{array}$ & \\
\hline
\end{tabular}

\author{
All comparisons were adjusted for \\ age, sex, smoking status, history of \\ diabetes, and usual body mass index \\ (BMI) (waist-to-hip ratio and waist \\ circumference were not adjusted for \\ usual BMI). Associations involve UK \\ Biobank data only. \\ a Hazard ratios are presented per 1-SD \\ higher usual risk factor level unless \\ otherwise indicated.
}

Our study identified potentially inverse associations of proatherogenic lipid levels with VTE. For example, apolipoprotein $B$ and lipoprotein(a) levels were each associated with lower risk of VTE, a finding that awaits further elucidation. ${ }^{41}$ Proinflammatory soluble biomarkers (eg, C-reactive protein) were positively associated with VTE, a finding consistent with the associations we observed for CHD outcomes. Although previous mendelian randomization studies suggest that CRP and fibrinogen levels are unlikely to be direct causal factors in $\mathrm{CHD},{ }^{42,43}$ such genetic epidemiological data are sparser in relation to VTE.

It is not clear why our study found inconsistent associations of blood pressure and history of diabetes with VTE outcomes across UK Biobank and the ERFC. One potential explanation is that these data sources recorded mostly differing types of VTE outcomes, ie, UK Biobank involved mostly nonfatal outcomes whereas ERFC involved only fatal outcomes. Our exploratory analysis of UK Biobank data was consistent with this explanation, as it found differing results with blood pressure and diabetes for fatal VTE vs nonfatal VTE similar to those observed in comparisons across UK Biobank and the ERFC. However, future studies with more detailed clinical information will be needed to understand these possible differences with greater confidence.

\section{Strengths and Limitations}

Our study had major strengths. It avoided the limitations of retrospective case-control study designs by analyzing prospective cohort data on more than 1.1 million participants without CVD at baseline. Access to individual participant data avoided the limitations of literature-based meta-analyses. It also enabled a common approach to adjustment for potential confounding factors, time-to-event analyses, correction for regression dilution bias, and head-to-head comparisons of VTE and CHD. We explored idiopathic VTE vs VTE provoked by established risk factors (such as cancer or prolonged immobility), albeit using pragmatic record-based definitions. ${ }^{44}$ The generalizability of our results was enhanced by inclusion of data from 75 prospective studies in ERFC recruited from 1960 through 2008 in 18 different countries. To enhance power and evaluate the relevance of findings to the contemporary situation, we included data from UK Biobank, which recruited participants from 2006 to 2010.

Our study also had limitations. We did not routinely have information in ERFC data on non-CVD risk factors for VTE (eg, oral contraception use) or medication use (eg, anticoagulants). Misclassification of disease outcomes could have arisen from inaccuracies in hospital discharge records and death certificates, diluting the strength of the observed associations. ${ }^{45-47}$ 


\begin{tabular}{|c|c|c|c|c|c|c|}
\hline Risk Factor & No. & $\begin{array}{l}\text { No. of } \\
\text { Events }\end{array}$ & $\begin{array}{l}\text { HR } \\
(95 \% \mathrm{Cl})\end{array}$ & & & $\begin{array}{l}\text { Difference } \\
P \text { Value }\end{array}$ \\
\hline \multicolumn{7}{|l|}{ Age (per decade) } \\
\hline Unprovoked VTE & 421537 & 1465 & $1.68(1.57-1.80)$ & & - & .001 \\
\hline Provoked VTE & 421537 & 856 & $2.07(1.88-2.28)$ & & \multicolumn{2}{|l|}{$\rightarrow$} \\
\hline \multicolumn{7}{|l|}{ Sex (male vs female) } \\
\hline Unprovoked VTE & 421537 & 1465 & $1.62(1.46-1.79)$ & & \multirow{2}{*}{-} & \multirow{2}{*}{$<.001$} \\
\hline Provoked VTE & 421537 & 856 & $1.18(1.03-1.35)$ & & & \\
\hline \multicolumn{7}{|c|}{ Smoking (current vs other) } \\
\hline Unprovoked VTE & 421537 & 1465 & $1.23(1.05-1.45)$ & & $\because-$ & \multirow[t]{2}{*}{.91} \\
\hline Provoked VTE & 421537 & 856 & $1.22(0.98-1.51)$ & & $\because-$ & \\
\hline \multicolumn{7}{|l|}{ Diabetes (yes vs no) } \\
\hline Unprovoked VTE & 421537 & 1465 & $0.78(0.62-0.99)$ & $\Longrightarrow$ & & \multirow[t]{2}{*}{.44} \\
\hline Provoked VTE & 421537 & 856 & $0.91(0.68-1.22)$ & $\longrightarrow$ & — & \\
\hline \multicolumn{7}{|c|}{ Alcohol consumption (current vs other) } \\
\hline Unprovoked VTE & 421197 & 1465 & $0.83(0.69-0.99)$ & $\longrightarrow$ & & \multirow[t]{2}{*}{.89} \\
\hline Provoked VTE & 421197 & 854 & $0.81(0.64-1.02)$ & $\because$ & & \\
\hline \multicolumn{7}{|c|}{ Systolic blood pressure } \\
\hline Unprovoked VTE & 421179 & 1460 & $0.86(0.78-0.95)$ & $\rightarrow$ & & \multirow[t]{2}{*}{.28} \\
\hline Provoked VTE & 421179 & 855 & $0.79(0.69-0.90)$ & $\rightarrow$ & & \\
\hline \multicolumn{7}{|c|}{ Diastolic blood pressure } \\
\hline Unprovoked VTE & 421181 & 1460 & $1.01(0.91-1.12)$ & & & \multirow[t]{2}{*}{.02} \\
\hline Provoked VTE & 421181 & 855 & $0.83(0.73-0.95)$ & $\rightarrow$ & & \\
\hline \multicolumn{7}{|l|}{ BMI } \\
\hline Unprovoked VTE & 421537 & 1465 & $1.40(1.34-1.46)$ & & - & \multirow[t]{2}{*}{.08} \\
\hline Provoked VTE & 421537 & 856 & $1.31(1.24-1.39)$ & & 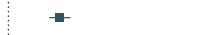 & \\
\hline \multicolumn{7}{|l|}{ Waist-to-hip ratio } \\
\hline Unprovoked VTE & 421440 & 1464 & $1.58(1.43-1.75)$ & & $\rightarrow$ & \multirow[t]{2}{*}{.21} \\
\hline Provoked VTE & 421440 & 855 & $1.42(1.24-1.63)$ & & -- & \\
\hline \multicolumn{7}{|l|}{ Waist circumference } \\
\hline Unprovoked VTE & 421464 & 1465 & $1.67(1.58-1.78)$ & & - & \multirow[t]{2}{*}{.01} \\
\hline \multirow[t]{3}{*}{ Provoked VTE } & 421464 & 855 & $1.47(1.35-1.60)$ & & - & \\
\hline & & & 0. & & $1 \quad 2$ & \multirow[t]{2}{*}{4} \\
\hline & & & & HR (95\% & $\begin{array}{l}\% \text { Cl) per 1-SD Higher } \\
\text { or Contrasta }\end{array}$ & \\
\hline
\end{tabular}

\begin{abstract}
All comparisons were adjusted for age, sex, smoking status, history of diabetes, and usual body mass index (BMI) (waist-to-hip ratio and waist circumference were not adjusted for usual BMI). Associations involve UK Biobank data only.

a Hazard ratios are presented per 1-SD higher usual risk factor level unless otherwise indicated.
\end{abstract}

However, 2 observations argue against major disease misclassification in our study. First, we observed associations of measures of adiposity with VTE risk similar in size to those previously reported in much smaller studies based on detailed validation of VTE events. ${ }^{6}$ Second, we observed directionally opposite associations of proatherogenic lipid levels with VTE and CHD outcomes despite the 2 conditions having similar clinical presentations.

\section{Conclusions}

Among a panel of several established cardiovascular risk factors, older age, smoking, and adiposity were consistently associated with higher VTE risk. There is overlap in at least some of the major population determinants of important venous and arterial thrombotic diseases.

\section{ARTICLE INFORMATION}

Accepted for Publication: November 15, 2018

Published Online: January 16, 2019. doi:10.1001/jamacardio.2018.4537

Open Access: This is an open access article distributed under the terms of the CC-BY License. (c) 2019 Gregson J et al. JAMA Cardiology.

Author Affiliations: London School of Hygiene and Tropical Medicine, London, United Kingdom (Gregson, Fletcher, Meade); MRC/BHF Cardiovascular Epidemiology Unit, Department of Public Health and Primary Care, University of Cambridge, Cambridge, United Kingdom (Kaptoge, Bolton, Pennells, Willeit, Burgess, Bell, Sweeting, Wood, Butterworth, Thompson, Danesh, Di Angelantonio); National Institute for Health
Research Blood and Transplant Research Unit in Donor Health and Genomics, University of Cambridge, Cambridge, United Kingdom (Kaptoge, Bolton, Bell, Butterworth, Danesh,

Di Angelantonio); Medical University of Innsbruck, Innsbruck, Austria (Willeit); MRC Biostatistics Unit, Cambridge University, Cambridge, United Kingdom (Burgess); Harvard T. H. Chan School of Public Health, Boston, Massachusetts (Rimm); Massachusetts General Hospital, Boston (Kabrhel); Department of Clinical Sciences, Lund University, Malmö, Sweden (Zöller, Svensson); Assmann Foundation for Prevention, Münster, Germany (Assmann); Icelandic Heart Association, Kópavogur, Iceland (Gudnason); University of Minnesota School of Public Health, Minneapolis (Folsom, Brenner); Division of Clinical Epidemiology and Aging
Research, German Cancer Research Center (DKFZ), Heidelberg, Germany (Arndt); University of Western Australia, Perth, Western Australia, Australia (Norman, Knuiman); Department of Clinical Biochemistry, Herlev and Gentofte Hospital, Copenhagen University Hospital, Copenhagen, Denmark (Nordestgaard); Faculty of Health and Medical Sciences, University of Copenhagen, Copenhagen, Denmark (Nordestgaard); Copenhagen City Heart Study, Frederiksberg Hospital, Copenhagen University Hospital, Copenhagen, Denmark (Nordestgaard); Osaka University, Osaka, Japan (Kitamura); University Medical Center Groningen, University of Groningen, Groningen, the Netherlands (Mahmoodi, Kromhout); St George's, University of London, London, United Kingdom (Whincup); National 
Institute for Health and Welfare, Helsinki, Finland (Salomaa); Ludwig Maximilian University of Munich, Munich, Germany (Meisinger, Nagel); Helmholtz Zentrum München, German Research Center for Environmental Health, Neuherberg, Germany (Meisinger); Deutsches Herzzentrum München, Technische Universität München, Munich, Germany (Koenig); German Centre for Cardiovascular Research (DZHK), partner site Munich Heart Alliance, Munich, Germany (Koenig); Department of Internal Medicine II-Cardiology, University of Ulm Medical Center, Ulm, Germany (Koenig); Erasmus University Medical Center, Erasmus University, Rotterdam, the Netherlands (Kavousi); University of Greifswald, Greifswald, Germany (Völzke, Sundström); UCL Medical School, University College London, London, United Kingdom (J. A. Cooper); Kyushu University, Fukuoka, Japan (Ninomiya); University of Padova, Padua, Italy (Casiglia); University of Hawaii, Honolulu (Rodriguez); Population Health Science, Bristo Medical School, University of Bristol, Bristol, United Kingdom (Ben-Shlomo, Gallacher, Lawlor); Institute of Nutraceuticals and Functional Foods, Université Laval, Quebec, Quebec, Canada (Després); The University of New South Wales, Sydney, New South Wales, Australia (Simons); University of California, San Diego (Barrett-Connor); University of Gothenburg, Gothenburg, Sweden (Björkelund Rosengren); Department of Internal Medicine, Bruneck Hospital, Bruneck, Italy (Notdurfter); University of Edinburgh, Edinburgh, United Kingdom (Price); Medical University of South Carolina, Charleston (Sutherland); Institute of Public Health and Clinical Nutrition, University of Eastern Finland, Kuopio, Finland (Kauhanen); VU University Medical Center Amsterdam, Amsterdam, the Netherlands (Beulens); Julius Center for Health Sciences and Primary Care, University Medical Center Utrecht, Utrecht University, Utrecht, the Netherlands (Beulens, van der Schouw Verschuren); Tel Aviv University, Tel Aviv, Israel (Dankner); MRC Lifecourse Epidemiology Unit, University of Southampton, Southampton, United Kingdom (C. Cooper); National Institute of Health (ISS), Rome, Italy (Giampaoli); Center of Health Equity, Diversity and Inclusion, University of Washington School of Medicine, Seattle (Deen): Clinical Research and Clinical Trials Unit, Plataforma de Innovación en Tecnologías Médicas y Sanitarias, Madrid, Spain (Gómez de la Cámara); University of Pittsburgh Graduate School of Public Health, Pittsburgh, Pennsylvania (Kuller); Portland State University, Portland, Oregon (Crespo); US Centers for Disease Control and Prevention, Atlanta, Georgia (Albertorio-Diaz); Monash University, Melbourne, Victoria, Australia (Atkins); Department of Epidemiology and Public Health, University College London, London, United Kingdom (Brunner, Shipley); Norwegian Institute of Public Health, Oslo, Norway (Njølstad, Selmer); MRC Integrative Epidemiology Unit at the University of Bristol, Bristol, United Kingdom (Lawlor); CUNY School of Medicine, City University of New York, New York (Trevisan); Centre for Nutrition, Prevention and Health Services, National Institute for Public Health and the Environment (RIVM), Bilthoven, the Netherlands (Verschuren); Feinberg School of Medicine, Northwestern University, Chicago, Illinois (Greenland); Albert Einstein College of Medicine, New York, New York

(Wassertheil-Smoller); Institute of Cardiovascular and Medical Sciences, University of Glasgow, Glasgow, United Kingdom (Lowe).

Author Contributions: Drs Kaptoge and Di Angelantonio had full access to all of the data in the study and take responsibility for the integrity of the data and the accuracy of the data analysis. Drs Gregson, Kaptoge, Danesh, Di Angelantonio, and Meade contributed equally.

Study concept and design: Gregson, Pennells, Rodriguez, Kromhout, Deen, Svensson, Trevisan, Wood, Danesh, Di Angelantonio, Meade. Acquisition, analysis, or interpretation of data Gregson, Kaptoge, Bolton, Pennells, Willeit, Burgess, Bell, Sweeting, Rimm, Kabrhel, Zöller, Assmann, Gudnason, Folsom, Arndt, Fletcher, Norman, Nordestgaard, Mahmoodi, Whincup, Knuiman, Salomaa, Meisinger, Koenig, Kavousi, Henry, J. Cooper, Ninomiya, Casiglia, Rodriguez, Ben-Shlomo, Després, Simons, Barrett-Connor, Björkelund, Notdurfter, Price, Sutherland, Sundstrom, Kauhanen, Gallacher, Beulens, Dankner, C. Cooper, Giampaoli, Gómez de la Cámara, Kuller, Rosengren, Nagel, Brenner, Albertorio-Diaz, Atkins, Shipley, Njølstad, Lawlor, van der Schouw, Selmer, Trevisan, Verschuren, Greenland, Wassertheil-Smoller, Lowe, Butterworth, Thompson, Danesh, Di Angelantonio. Drafting of the manuscript: Gregson, Bolton, Notdurfter, C. Cooper, Deen, Danesh, Di Angelantonio, Meade. Critical revision of the manuscript for important intellectual content: Kaptoge, Bolton, Pennells, Willeit, Burgess, Bell, Sweeting, Rimm, Kabrhel, Zöller, Assmann, Gudnason, Folsom, Arndt, Fletcher, Norman, Nordestgaard, Mahmoodi, Whincup, Knuiman, Salomaa, Meisinger, Koenig, Kavousi, Henry, J. Cooper, Ninomiya, Casiglia, Rodriguez, Ben-Shlomo, Després, Simons Barrett-Connor, Björkelund, Kromhout, Price, Sutherland, Sundstrom, Kauhanen, Gallacher Beulens, Dankner, C. Cooper, Giampaoli, Deen, Gómez de la Cámara, Kuller, Rosengren, Svensson, Nagel, Brenner, Albertorio-Diaz, Atkins, Shipley, Njølstad, Lawlor, van der Schouw, Selmer, Trevisan, Verschuren, Greenland, Wassertheil-Smoller, Lowe, Wood, Butterworth, Thompson, Danesh, Di Angelantonio, Meade.

Statistical analysis: Gregson, Kaptoge, Bolton, Pennells, Burgess, Sweeting, Sutherland, C. Cooper, Albertorio-Diaz, Lawlor, Wood, Thompson. Obtained funding: Nordestgaard, Henry, Casiglia, Rodriguez, Simons, Kromhout, Sutherland,

Gallacher, Rosengren, Lawlor, Wassertheil-Smoller Danesh, Di Angelantonio.

Administrative, technical, or material support: Bolton, Bell, Kabrhel, Zöller, Fletcher, Whincup, Salomaa, Casiglia, Rodriguez, Simons, Björkelund, Notdurfter, Kromhout, Sutherland, Kauhanen Beulens, Dankner, Kuller, Svensson, Nagel, Atkins, Trevisan, Verschuren, Lowe, Danesh.

Study supervision: Kaptoge, Willeit, Rimm, Kabrhel Gudnason, Salomaa, Koenig, Kavousi, Casiglia Rodriguez, Simons, Kromhout, Kauhanen,

Svensson, Trevisan, Butterworth, Danesh, Meade.

Conflict of Interest Disclosures: Dr Gregson has received grants from AstraZeneca and BioSensors as well as personal fees from BioSensors, Edwards Lifesciences, and MvRX. Dr Kaptoge has received grants from the British Heart Foundation and the UK Medical Research Council paid to the Department of Public Health and Primary Care of the University of Cambridge. Dr Kabrhel has received grant HL116854 from the National Heart,
Lung, and Blood Institute as well as grants from Diagnostica Stago, Janssen Pharmaceuticals, and Siemens Healthcare Diagnostics. Dr Salomaa has received personal fees from Novo Nordisk. Dr Koenig has received grants and nonfinancial support from Abbott, Beckmann, Roche Diagnostics, and Singulex as well as personal fees from AstraZeneca, Novartis, Pfizer, The Medicines Company, GlaxoSmithKline, DalCor, Kowa, and Amgen for consulting and from AstraZeneca, Sanofi, and Berlin-Chernie for lectures. Dr Lawlor has received grants from the UK Medical Research Council, UK Economic and Social Science Research Council, British Heart Foundation, Diabetes UK European Research Council, and National Institute for Health as well as funds in kind from Medtronic and Roche Diagnostics paid to the University of Bristol. Dr Butterworth has received grants from AstraZeneca, Biogen, Merck, Novartis, and Pfizer. Dr Thompson has received grants from British Heart Foundation and the UK Medical Research Council. No other disclosures were reported.

Funding/Support: This research has been conducted using the UK Biobank resource under Application Number 26865. This work was supported by underpinning grants from the UK Medical Research Council (grant G0800270), the British Heart Foundation (grant SP/09/002), the British Heart Foundation Cambridge Cardiovascular Centre of Excellence, UK National Institute for Health Research Cambridge Biomedical Research Centre, European Research Council (grant 268834) , the European Commission Framework Programme 7 (grant HEALTH-F2-2012-279233), and Health Data Research UK. Dr Danesh holds a British Heart Foundation Personal Chair and a National Institute for Health Research Senior Investigator Award.

Role of the Funder/Sponsor: The funders had no role in the design and conduct of the study; collection, management, analysis, and interpretation of the data; preparation, review, or approval of the manuscript; and decision to submit the manuscript for publication.

Group Information: Investigators of the Emerging Risk Factors Collaboration include the following: Atherosclerosis Risk in Communities Study: Wayne Rosamond, PhD; Eric Whitsel, PhD; and Mary Cushman, BSc (University of North Carolina, Chape Hill); Australian Diabetes Study: Elizabeth L. M. Barr, PhD; Jonathan E. Shaw, MD; and Paul Z. Zimmet, MD (Baker Heart and Diabetes Institute, Melbourne, Victoria, Australia); Busselton Health Study: Matthew Knuiman, PhD (The University of Western Australia, Perth, Western Australia, Australia); British Regional Heart Study: Peter $\mathrm{H}$. Whincup, PhD (St George's, University of London, London, United Kingdom); Bruneck Study: Stefan Kiechl, MD; Siegfried Weger, MD; and Johann Willeit, MD (Department of Internal Medicine, Bruneck Hospital, Italy); British Women's Heart and Health Study: Deborah A. Lawlor, PhD (University of Bristol, Bristol, United Kingdom); Antoinette Amuzu, MA; Caroline Dale, PhD; and Juan P. Casas, MD (University College London, London, United Kingdom); Caerphilly Prospective Study: John Gallacher, PhD (University of Oxford, Oxford United Kingdom); Cardiovascular Study in the Elderly: Valérie Tikhonoff, MD (University of Padua, Padua, Italy); Chicago Heart Association Detection Project In Industry: Philip Greenland, MD (Northwestern University, Chicago, Illinois); Charleston Heart Study: Paul Nietert, PhD (Medical 
University of South Carolina, Charleston): Copenhagen City Heart Study: Anne Tybjærg-Hansen, MD; Ruth Frikke-Schmidt, MD; and Gorm B. Jensen, MD (University of Copenhagen, Copenhagen, Denmark); Diet and Risk of Cardiovascular Disease in Spain: David Lora Pablos, MD; and Pilar Cancelas Navia, MD (Hospital 12 de Octubre, Madrid, Spain); Dubbo Study of the Elderly: Leon Simons, MD (University of New South Wales, Sydney, New South Wales, Australia); Edinburgh Artery Study: Stela McLachlan, PhD (The University of Edinburgh, Edinburgh, United Kingdom); Epidemiologische Studie zu Chancen der Verhutung und optimierten Therapie chronischer Erkrankungen in der alteren Bevolkerung: Ben Schöttker, MD; Kai-Uwe Saum, PhD; and Bernd Holleczek, PhD (German Cancer Research Center, Heidelberg, Germany); Oslo Study, Cohort of Norway: Inger Ariansen, PhD; Haakon E. Meyer MD; and Lise Lund Håheim, MD (Norwegian Institute of Public Health, Oslo, Norway); Finrisk Cohort 1992, Finrisk Cohort 1997: Erkki Vartiainen, MD; Pekka Jousilahti, MD; and Kennet Harald, MD (National Institute for Health and Welfare, Helsinki, Finland); The Glucose Intolerance, Obesity and Hypertension Study: Rachel Dankner, MD (Tel Aviv University, Tel Aviv, Israel); Goteborg Study 1933, MONICA Göteborg Study: Annika Rosengren, MD and Lars Wilhelmsen, MD (University of Gothenburg, Gothenburg, Sweden); Population Study of Women in Göteborg, Sweden: Cecilia Björkelund, MD (University of Gothenburg Gothenburg, Sweden); Göttingen Risk Incidence and Prevalence Study: Dorothea Nagel, MD (German Cancer Research Center, Heidelberg, Germany); Hertfordshire Cohort Study: Elaine Dennison, PhD; Holly Syddall, PhD; and Leo Westbury, MSc (University of Southampton, Southampton, United Kingdom); Health in Men Study: Leon Flicker, PhD; Graeme J. Hankey, MD (University of Western Australia, Perth, Western Australia, Australia); and Jonathan Golledge, MD (James Cook University Townsville, Queensland, Australia); Hisayama Study: Toshiharu Ninomiya, PhD; Yasufumi Doi, PhD; and Yutaka Kiyohara, PhD (Kyushu University, Fukuoka, Japan); Honolulu Heart Program: Beatriz Rodriguez, MD (University of Hawaii, Honolulu); Hoorn Study: Petra Elders, MD; and Coen Stehouwer, MD (VU University Medical Center, Amsterdam, the Netherlands); Health Professionals Follow-up Study: Christopher Kabrhel, MD (Massachusetts General Hospital, Boston); and Majken Jensen, PhD (Harvard T. H. Chan School of Public Health, Boston, Massachusetts); Ikawa, Kyowa, and Noichi Study: Akihiko Kitamura, MD (Tokyo Metropolitan Institute of Gerontology, Tokyo, Japan); Hiroyasu Iso, MD (Osaka University Graduate School of Medicine, Suita, Japan); and Kazumasa Yamagishi, MD (University of Tsukuba, Tsukuba, Japan); North Karelia Project: Veikko Salomaa, MD (National Institute for Health and Welfare, Helsinki, Finland); Kuopio Ischaemic Heart Disease Study: Kurl Sudhir, MD; Tomi-Pekka Tuomainen, PhD; and Jukka T. Salonen, MD (University of Eastern Finland, Keupio, Finland); Lower Extremity Arterial Disease Event Reduction Trial, Northwick Park Heart Study II: Jackie A. Cooper, MBBS, (UCL Medical School, University College London, London, United Kingdom); Monitoring of CVD Risk Factors Project, Dutch Monitoring Project on Risk Factors for Chronic Diseases: Jolanda M. A. Boer, PhD; and Anneke Blokstra, PhD (National Institute for Public Health and the Environment [RIVM], Bilthoven, the Netherlands); Malmö Diert and Cancer Cardiovascular Study, Malmö Preventive Project: Olle Melander, MD; Peter M. Nilsson, MD; and Gunnar Engström, PhD (Lund University, Lund, Sweden); Risk Factors and Life Expectancy Pooling Project, Risk Factors and Life Expectancy Pooling Project: Maurizio Trevisan, MD (The City College of New York, New York); Progetto CUORE: Luigi Palmieri, MD; Diego Vanuzzo, MD; and Simona Giampaoli, MD (National Health Institute of Health [ISS], Rome, Italy); MONICA/KORA Augsburg Survey S1, MONICA/KORA Augsburg Survey S2, MONICA/ KORA Augsburg Survey S3: Annette Peters, MD; Barbara Thorand, PhD; and Margit Heier, PhD (German Research Center for Environmental Health, Neuherberg, Germany); MRC Study of Older People: Astrid Fletcher, MD (London School of Hygiene and Tropical Medicine, London, United Kingdom); Multiple Risk Factor Intervention Trial 1: Lewis H. Kuller, PhD (University of Pittsburgh Graduate School of Public Health, Pittsburgh, Pennsylvania); National Health and Nutrition Examination Survey I: Juan R. Albertorio-Diaz, MA (US Centers for Disease Control and Prevention, Atlanta, Georgia); Nurses' Health Study: Eric B. Rimm, ScD; Frank B. Hu, MD; and JoAnn E. Manson, MD (Harvard T. H. Chan School of Public Health, Boston, Massachusetts); Prevention of Renal and Vascular End Stage Disease Study: Karina Meijer, MD; Ron T. Gansevoort, MD (University of Groningen, Groningen, the Netherlands); Puerto Rico Heart Health Program: Carlos J. Crespo, MD (Portland State University, Portland, Oregon); Prospective Cardiovascular Münster Study: Gerd Assmann, MD (Assmann Foundation for Prevention, Münster, Germany); and Helmut Schulte, PhD (University of Münster, Münster, Germany); Prospect EPIC Utrecht: Ivonne Sluijs, PhD (University Medical Center Utrecht, Utrecht, the Netherlands); Quebec Cardiovascular Study: Bernard Cantin, PhD; Benoît Lamarche, PhD; and Gilles R. Dagenais, MD (Université Laval, Quebec, Quebec, Canada); Rancho Bernardo Study: Linda McEvoy, PhD; Gail Laughlin, PhD; and Lori B. Daniels, MD (University of California, San Diego): Reykjavik Study: Thor Aspelund, PhD; Elías Freyr Gudmundsson, PhD; and Bolli Thorsson, PhD (University of Iceland, Reykjavík, Iceland); The Rotterdam Study: Maarten J. G. Leening, PhD; M. Arfan Ikram, MD; and Oscar H. Franco, MD (Erasmus Medical Centre, Rotterdam, the Netherlands); Scottish Heart Health Extended Cohort: Hugh Tunstall-Pedoe, MD (Dundee University, Dundee, United Kingdom); Study of Health in Pomerani: Henry Völzke, MD; and André Werner, MD (University of Greifswald, Greifswald, Germany); Strong Heart Study: Richard Devereux, MD (Weill Cornell Medicine, New York, New York); and Stacey Jolly, MD (Cleveland Clinic, Phoenix, Arizona); Speedwell Study: George Davey Smith, MD (Bristol University, Bristol, United Kingdom); Turkish Adult Risk Factor Study: Günay Can, MD (Trakya University, Edime, Turkey); Hüsniye Yüksel, MD (Ataşehir Florence Nightingale Hospital, Istanbul, Turkey); and Servet Altay, MD (Trakya University, Edime, Turkey); Tromsø Study: Inger Njølstad, MD (The Arctic University of Norway, Tromsø, Norway); Uppsala Longitudinal Study of Adult Men: Martin Ingelsson, MD; and Vilmantas Giedraitis, PhD (Uppsala University, Uppsala, Sweden); Wuertemberg Construction Workers Cohort: Hermann Brenner, MD (German Cancer
Research Center, Heidelberg, Germany); Heiner Claessen, PhD (German Diabetes Center, Düsseldorf, Germany); and Dietrich Rothenbacher, MD (University of Ulm, Ulm, Germany); Women's Health Initiative: Nisha I. Parikh, MD (University of California, San Francisco); and Charles Eaton, MD (Care New England, Pawtucket, Rhode Island); Whitehall I Study: Martin Shipley, MSc; and Mika Kivimaki, FMedSci (University College London, London, United Kingdom); Whitehall II Study: Eric J. Brunner, PhD; and Martin Shipley, MSc (University College London, London, United Kingdom); and Zutphen Elderly Study: Edith Feskens, MD; Johanna M. Geleijnse, MD; and Daan Kromhout, MD (Wageningen University, Wageningen, the Netherlands); Data Management Team: Thomas Bolton, MSc; Sarah Spackman, MMath; and Matthew Walker, PhD (MRC/BHF Cardiovascular Epidemiology Unit, Department of Public Health and Primary Care, University of Cambridge, Cambridge, United Kingdom). Coordinating Centre: Thomas Bolton, MSc; Stephen Burgess, PhD; Adam S. Butterworth, PhD; Emanuele Di Angelantonio, FRCP; Stephen Kaptoge, PhD; Lisa Pennells, PhD Sarah Spackman, MMath; Simon G. Thompson, PhD; Matthew Walker, PhD; Angela M. Wood, PhD; and John Danesh, FMedSci (principal investigator) (MRC/BHF Cardiovascular Epidemiology Unit, Department of Public Health and Primary Care, University of Cambridge, Cambridge, United Kingdom).

\section{REFERENCES}

1. Di Nisio M, van Es N, Büller HR. Deep vein thrombosis and pulmonary embolism. Lancet. 2016;388(10063):3060-3073. doi:10.1016/S01406736(16)30514-1

2. Goldhaber SZ, Bounameaux H. Pulmonary embolism and deep vein thrombosis. Lancet. 2012; 379(9828):1835-1846. doi:10.1016/S0140-6736(11) 61904-1

3. Goldhaber SZ. Risk factors for venous thromboembolism. J Am Coll Cardiol. 2010;56(1):17. doi:10.1016/j.jacc.2010.01.057

4. Lowe GD. Common risk factors for both arterial and venous thrombosis. Br J Haematol. 2008:140 (5):488-495. doi:10.1111/j.1365-2141.2007.06973.x

5. Abdollahi M, Cushman M, Rosendaal FR. Obesity: risk of venous thrombosis and the interaction with coagulation factor levels and oral contraceptive use. Thromb Haemost. 2003;89(3): 493-498. doi:10.1055/s-0037-1613379

6. Ageno W, Becattini C, Brighton T, Selby R, Kamphuisen PW. Cardiovascular risk factors and venous thromboembolism: a meta-analysis. Circulation. 2008;117(1):93-102. doi:10.1161/ CIRCULATIONAHA.107.709204

7. Bai J, Ding X, Du X, Zhao X, Wang Z, Ma Z. Diabetes is associated with increased risk of venous thromboembolism: a systematic review and meta-analysis. Thromb Res. 2015;135(1):90-95. doi: 10.1016/j.thromres.2014.11.003

8. Bell EJ, Folsom AR, Lutsey PL, et al. Diabetes mellitus and venous thromboembolism: a systematic review and meta-analysis. Diabetes Res Clin Pract. 2016;111:10-18. doi:10.1016/j.diabres. 2015.10.019

9. Cheng Y-J, Liu Z-H, Yao F-J, et al. Current and former smoking and risk for venous thromboembolism: a systematic review and 
meta-analysis. PLoS Med. 2013;10(9):e1001515. doi: 10.1371/journal.pmed.1001515

10. Glynn RJ, Rosner B. Comparison of risk factors for the competing risks of coronary heart disease, stroke, and venous thromboembolism. Am J Epidemiol. 2005;162(10):975-982. doi:10.1093/aje/ kwi309

11. Glynn RJ, Danielson E, Fonseca FAH, et al. A randomized trial of rosuvastatin in the prevention of venous thromboembolism. N Engl J Med. 2009; 360(18):1851-1861. doi:10.1056/NEJMoa0900241

12. Holst AG, Jensen G, Prescott E. Risk factors for venous thromboembolism: results from the Copenhagen City Heart Study. Circulation. 2010;121 (17):1896-1903. doi:10.1161/CIRCULATIONAHA.109. 921460

13. Mahmoodi BK, Cushman M, Anne Næss I, et al. Association of traditional cardiovascular risk factors with venous thromboembolism: an individual participant data meta-analysis of prospective studies. Circulation. 2017;135(1):7-16. doi:10.1161/ CIRCULATIONAHA.116.024507

14. Tsai AW, Cushman M, Rosamond WD, Heckbert SR, Polak JF, Folsom AR. Cardiovascular risk factors and venous thromboembolism incidence: the longitudinal investigation of thromboembolism etiology. Arch Intern Med. 2002;162(10):1182-1189. doi:10.1001/archinte.162.10.1182

15. Wattanakit K, Lutsey PL, Bell EJ, et al. Association between cardiovascular disease risk factors and occurrence of venous thromboembolism: a time-dependent analysis. Thromb Haemost. 2012:108(3):508-515.

16. Cushman M, Tsai AW, White RH, et al. Deep vein thrombosis and pulmonary embolism in two cohorts: the longitudinal investigation of thromboembolism etiology. Am J Med. 2004;117(1): 19-25. doi:10.1016/j.amjmed.2004.01.018

17. Deguchi H, Pecheniuk NM, Elias DJ, Averell PM Griffin JH. High-density lipoprotein deficiency and dyslipoproteinemia associated with venous thrombosis in men. Circulation. 2005;112(6):893-899. doi:10.1161/CIRCULATIONAHA.104.521344

18. Doggen CJM, Smith NL, Lemaitre RN, Heckbert SR, Rosendaal FR, Psaty BM. Serum lipid levels and the risk of venous thrombosis. Arterioscler Thromb Vasc Biol. 2004;24(10):1970-1975. doi:10.1161/01. ATV.0000143134.87051.46

19. Hansson PO, Eriksson H, Welin L, Svärdsudd K, Wilhelmsen L. Smoking and abdominal obesity: risk factors for venous thromboembolism among middle-aged men: "the study of men born in 1913." Arch Intern Med. 1999;159(16):1886-1890. doi:10. 1001/archinte.159.16.1886

20. Høibraaten $E$, Abdelnoor $M$, Sandset $P M$. Hormone replacement therapy with estradiol and risk of venous thromboembolism: a population-based case-control study. Thromb Haemost. 1999;82(4):1218-1221.

21. Kawasaki T, Kambayashi J, Ariyoshi H, Sakon M, Suehisa E, Monden M. Hypercholesterolemia as a risk factor for deep-vein thrombosis. Thromb Res 1997;88(1):67-73. doi:10.1016/S0049-3848(97) 00192-8

22. Lidegaard Ø, Edström B, Kreiner S. Ora contraceptives and venous thromboembolism: a five-year national case-control study. Contraception. 2002;65(3):187-196. doi:10.1016/S0010-7824(01) 00307-9

23. McColl MD, Sattar N, Ellison J, et al. Lipoprotein (a), cholesterol and triglycerides in women with venous thromboembolism. Blood Coagul Fibrinolysis. 2000;11(3):225-229.

24. Prandoni P, Bilora F, Marchiori A, et al. An association between atherosclerosis and venous thrombosis. NEngl J Med. 2003;348(15):1435-1441. doi:10.1056/NEJMoa022157

25. Severinsen MT, Kristensen SR, Johnsen SP, Dethlefsen C, Tjønneland A, Overvad K. Smoking and venous thromboembolism: a Danish follow-up study. J Thromb Haemost. 2009;7(8):1297-1303. doi:10.1111/j.1538-7836.2009.03490.x

26. Gariani K, Mavrakanas T, Combescure C, Perrier A, Marti C. Is diabetes mellitus a risk factor for venous thromboembolism? a systematic review and meta-analysis of case-control and cohort studies. Eur J Intern Med. 2016;28:52-58. doi:10. 1016/j.ejim.2015.10.001

27. Danesh J, Erqou S, Walker M, et al; Emerging Risk Factors Collaboration. The Emerging Risk Factors Collaboration: analysis of individual data on lipid, inflammatory and other markers in over 1.1 million participants in 104 prospective studies of cardiovascular diseases. Eur J Epidemiol. 2007;22 (12):839-869. doi:10.1007/s10654-007-9165-7

28. Sudlow C, Gallacher J, Allen N, et al. UK biobank: an open access resource for identifying the causes of a wide range of complex diseases of middle and old age. PLoS Med. 2015;12(3):e1001779. doi:10.1371/journal.pmed.1001779

29. Wood AM, White I, Thompson SG, Lewington S, Danesh J; Fibrinogen Studies Collaboration. Regression dilution methods for meta-analysis: assessing long-term variability in plasma fibrinogen among 27,247 adults in 15 prospective studies. Int $J$ Epidemiol. 2006;35(6):1570-1578. doi:10.1093/ ije/dyl233

30. Plummer M. Improved estimates of floating absolute risk. Stat Med. 2004;23(1):93-104. doi:10 1002/sim.1485

31. Lunn M, McNeil D. Applying Cox regression to competing risks. Biometrics. 1995;51(2):524-532. doi:10.2307/2532940

32. Wood AM, Kaptoge S, Butterworth AS, et al Emerging Risk Factors Collaboration/EPIC-CVD/UK Biobank Alcohol Study Group. Risk thresholds for alcohol consumption: combined analysis of individual-participant data for 599912 current drinkers in 83 prospective studies. Lancet. 2018;391 (10129):1513-1523. doi:10.1016/S0140-6736(18) 30134-X

33. Klovaite J, Benn M, Nordestgaard BG. Obesity as a causal risk factor for deep venous thrombosis: a mendelian randomization study. J Intern Med. 2015;277(5):573-584. doi:10.1111/joim.12299

34. Lindström S, Germain M, Crous-Bou M, et al; INVENT Consortium. Assessing the causa relationship between obesity and venous thromboembolism through a mendelian randomization study. Hum Genet. 2017;136(7):897 902 doi:10.1007/s00439-017-1811-x
35. Blondon M, Wiggins KL, McKnight B, et al. The association of smoking with venous thrombosis in women: a population-based, case-control study. Thromb Haemost. 2013;109(5):891-896. doi:10. 1160/TH12-10-0732

36. Enga KF, Braekkan SK, Hansen-Krone IJ, le Cessie S, Rosendaal FR, Hansen J-B. Cigarette smoking and the risk of venous thromboembolism: the Tromsø Study. J Thromb Haemost. 2012;10 (10):2068-2074. doi:10.1111/j.1538-7836.2012.04880.

37. Harrington LB, Hagan KA, Mukamal KJ, et al. Alcohol consumption and the risk of incident pulmonary embolism in US women and men. J Thromb Haemost. 2018;16(9):1753-1762. doi:10. 1111/jth.14224

38. Lippi G, Mattiuzzi C, Franchini M. Alcoho consumption and venous thromboembolism: friend or foe? Intern Emerg Med. 2015;10(8):907-913. doi: 10.1007/s11739-015-1327-0

39. Mukamal KJ, Jadhav PP, D'Agostino RB, et al Alcohol consumption and hemostatic factors: analysis of the Framingham Offspring cohort. Circulation. 2001;104(12):1367-1373. doi:10.1161/ hc3701.096067

40. Lee KW, Lip GY. Effects of lifestyle on hemostasis, fibrinolysis, and platelet reactivity: a systematic review. Arch Intern Med. 2003;163(19) 2368-2392. doi:10.1001/archinte.163.19.2368

41. Morelli VM, Lijfering WM, Bos MHA, Rosendaal FR, Cannegieter SC. Lipid levels and risk of venous thrombosis: results from the MEGA-study. Eur J Epidemiol. 2017;32(8):669-681. doi:10.1007/s10654 017-0251-1

42. Wensley F, Gao P, Burgess S, et al; C Reactive Protein Coronary Heart Disease Genetics Collaboration (CCGC). Association between C reactive protein and coronary heart disease: mendelian randomisation analysis based on individual participant data. BMJ. 2011;342:d548. doi:10.1136/bmj.d548

43. Davey Smith G, Harbord R, Ebrahim S. Fibrinogen, C-reactive protein and coronary heart disease: does mendelian randomization suggest the associations are non-causal? QJM. 2004;97(3):163166. doi:10.1093/ajmed/hch025

44. Lapner ST, Kearon C. Diagnosis and management of pulmonary embolism. BMJ. 2013 346:f757. doi:10.1136/bmj.f757

45. Dismuke SE, VanderZwaag R. Accuracy and epidemiological implications of the death certificate diagnosis of pulmonary embolism. J Chronic Dis. 1984;37(1):67-73. doi:10.1016/0021-9681(84)90127-

46. Miniati $M$, Prediletto R, Formichi $B$, et al Accuracy of clinical assessment in the diagnosis of pulmonary embolism. Am J Respir Crit Care Med. 1999;159(3):864-871. doi:10.1164/ajrccm.159.3. 9806130

47. Stein PD, Henry JW. Prevalence of acute pulmonary embolism among patients in a general hospital and at autopsy. Chest. 1995;108(4):978-981. doi:10.1378/chest.108.4.978 